\title{
PLASMA POWER IMPACT ON ELECTROCHEMICAL PERFORMANCE OF LOW CARBON STEEL COATED BY PLASMA THIN TEOS FILMS
}

\author{
Amr Gangan ${ }^{a}$, Mansour ElSabbagh ${ }^{b}$ M.A. Bedair ${ }^{\mathrm{c}, a}$, M. M. B. El-Sabbah ${ }^{\mathrm{a}}$, Alaa \\ Fahmy a* \\ ${ }^{a}$ Department of Chemistry, Faculty of Science, Al-Azhar University, Nasr City 11884, Cairo, Egypt. \\ ${ }^{\mathrm{b}}$ Physics Department and Plasma Center, Faculty of Science, Al Azhar University, 11884 Cairo, Egypt. \\ c College of Science and arts, University of Bisha, Al-Namas 61977, P.O. Box 101, Saudi Arabia.
}

Corresponding author*: Alaa Fahmy, PhD (Associate Prof.); Email: alaa.fahmy@azhar.edu.eg

\begin{abstract}
Electrochemical properties of thin silicon oxy carbide films were investigated as anticorrosive coatings. The film was deposited on low carbon steel substrate by radio frequency capacitive coupled plasma technique using tetraethyl ortho silicate (TEOS) as a precursor and Ar was used as a carrier gas in dependence on the applied power. The chemical composition and morphological of the deposited films were examined by energydispersive X-ray spectroscopy (EDX) coupled with scanning electron microscopy (SEM). The SEM results confirm a pinhole-free layer of oxy carbide was formed on the steel surface after plasma treatment.

The corrosion resistance of the coatings was analyzed by potentiodynamic polarization and electrochemical spectroscopy (EIS) in $3.5 \% \mathrm{NaCl}$ solution at room temperature. The electrochemical results show remarkable corrosion resistance enhancement after plasma treatments. The corrosion current $\left(\mathrm{i}_{\text {corr }}\right)$ is significantly reduced from $12 \mu \mathrm{A} / \mathrm{cm}^{2}$ for the blank sample to 1 and $0.3 \mu \mathrm{A} / \mathrm{cm}^{2}$ for treated samples at 50 , and $100 \mathrm{~W}$, respectively. A marked increase of the protective properties was detected by $100 \mathrm{~W}$ sample with protective efficiency more than $98 \%$ at room temperature.
\end{abstract}

Keywords: Corrosion resistance; Mild steel; Plasma treatments; Tetraethyl ortho silicate; Thin film

\section{INTRODUCTION}

Almost metals, particularly carbon steel, are thermodynamically unstable therefore, they corrode especially when they are in contact with oxygen and water. Moreover, the corrosion destroys millions of tons of carbon steel over the world per year [1,2].Over the years, numerous numbers of studies that concerned with different methods for the protection of metals against corrosion to provide wide utilization of these metals. An effective way to retard corrosion of carbon steel by coating its surfaces with thin films which act as barriers against corrosion [3-7]. These films were applied to steel surface by different methodologies such as electrodeposition [8], hot dipping [9], sol-gel [8,9], chemical vapor deposition, and plasma-enhanced chemical vapor deposition (PECVD) [10-12]. However, the plasma-enhanced process is a promising technology for metals surface modification in terms of corrosion resistance enhancement [15]. This process is simple, economically feasible, and environmentally friendly.
The plasma deposited $\mathrm{SiO}_{\mathrm{x}}$ thin films from organosilicon precursors manifest an attractive approach to enhancement of the corrosion resistance of carbon steel. The deposited $\mathrm{SiO}_{x}$ films showed excellent stability, flexibility, and smoothness [1].

Yung-Sen et al. [16] prepared protective coating on the steel surface by using a mixture of tetraethyl ortho silicate (TEOS) and $\mathrm{H}_{2}$ at room temperature. They found that great improvement of electrochemical properties after immersion in $3.5 \% \mathrm{NaCl}$ solution for 10 days. Rangel et al. [1] investigate the electrochemical properties of $\mathrm{SiO}_{\mathrm{x}} / \mathrm{SiO}_{\mathrm{x}} \mathrm{C}_{\mathrm{y}} \mathrm{H}_{\mathrm{z}}$ films in $3.5 \% \mathrm{NaCl}$ solution too. The film was deposited by low-pressure radio frequency (13.56 MHz) plasmas using HMDSO, Ar and $\mathrm{O}_{2}$ mixtures. It was noted that the total corrosion resistance increased by six orders of magnitude when carbon steel was coated with a $2 \mu \mathrm{m}$ film. Delimi et al. [14] employed a mixture of $\mathrm{SiH}_{4}\left(3 \%\right.$ in $\left.\mathrm{N}_{2}\right)$ and $\mathrm{N}_{2} \mathrm{O}$ gas to deposit $\mathrm{SiO}_{\mathrm{x}}$ coatings on carbon steel with a thickness between 20 and $200 \mathrm{~nm}$. They 
examined the corrosion protection efficiency in an aqueous saline solution $3 \% \mathrm{NaCl}$ and report that thin $\mathrm{SiO}_{\mathrm{x}}$-like coating layers (20 nm thick) do not prevent the carbon steel from corrosion, while thicker silica layers $(\mathrm{d} \geq 100 \mathrm{~nm})$ protect efficiently carbon steel interfaces in highly saline media with a protection efficiency of about $96 \%$ for a $200 \mathrm{~nm}$ thick coating. Saloum et al. [17] revealed the corrosion protection of plasma polymerized thin Hexamethyldisilane (HMDSO) films in $0.3 \mathrm{M} \mathrm{NaCl}$ and $0.3 \mathrm{M}$ $\mathrm{H}_{2} \mathrm{SO}_{4}$. A promising corrosion protection property of the thin HMDSO films was obtained. Ponton et al. [18] prepared thin and dense $\mathrm{SiO}_{2}$ films from tetraethyl ortho silicate $\left(\mathrm{Si}\left(\mathrm{OC}_{2} \mathrm{H}_{5}\right)_{4}\right.$, TEOS $)$ using chemical vapor deposition (CVD) in the range of temperature from 400 to $550 \quad{ }^{\circ} \mathrm{C}$ with effective electrochemical properties.

In summary, the organic silicon compounds like TEOS may be the right choice for the deposition of good and uniform thin films of silicon oxide $\left(\mathrm{SiO}_{2}\right)$, which may provide good protection for carbon steel against corrosion.

This work aims to prepare protective coatings on carbon steel by applying TEOS as a precursor plasma technique based on plasma power. Furthermore, topography, elemental analysis, and the electrochemical properties of the protective films were examined.

\section{MATERIALS AND EXPERIMENTAL METHODS}

\subsection{Materials}

Mild carbon steel substrates obtained from Central Metallurgical Research Institute, with composition of (in wt\%) $0.271 \%$ C, $0.214 \%$ $\mathrm{Si}, 0.829 \% \mathrm{Mn}, 0.0305 \% \mathrm{P}, 0.0156 \% \mathrm{~S}$, $0.0122 \% \mathrm{Cr}, 0.0187 \% \mathrm{Ni}, 0.00332 \% \mathrm{Al}$, $0.0041 \% \mathrm{Co}, 0.0071 \% \mathrm{Cu}, 0.00014 \% \mathrm{Ti}$, $0.00275 \% \mathrm{~V}, 0.00951 \% \mathrm{~W}, 0.00951 \% \mathrm{~Pb}$, $0.0108 \%$ As, $0.0003 \% \mathrm{~B}$ and $98.57 \% \mathrm{Fe}$ was used in this study.

For all the experiments, the cylindrical carbon steel samples with dimensions $(25 \mathrm{~mm}$ in diameter and $5 \mathrm{~mm}$ in height) were polished with silicon carbide emery papers with different grades $(60,80,120,400,800,1000$ and 2000) to produce a fine surface. After that, the samples were washed with acetone and dried at room temperature before use.

Tetraethyl orthosilicate (TEOS) $\mathrm{Si}\left(\mathrm{OC}_{2} \mathrm{H}_{5}\right)_{4}$ with molar mass $208 \mathrm{~g} / \mathrm{mol}$ was obtained from Sigma-Aldrich analytical grade $99 \%$.

\subsection{Corrosive solutions}

Sodium chloride $(\mathrm{NaCl})$ with analytical grade $99.99 \%$ was used to preparea3.5\% saline solution in deionized water for electrochemical characterization.

\subsection{Plasma deposition method}

The plasma discharge was generated in a stainless-steel reactor chamber using radio frequency plasma produced by a power supply (RFG-1K-13, UK) with $13.6 \mathrm{MHz}$ and continuous out power ranging from 0 to $1000 \mathrm{~W}$. The schematic representation of the experimental set-up is shown in Fig. 1. The steel substrates were then placed in the plasma chamber as electrodes at room temperature. Subsequently, the chamber was pumped down to $300 \mathrm{~m}$ Torr using a vacuum pump. Thereafter, the Ar gas was introduced into the bubbler system containing (TEOS) liquid and carry the TEOS vapor into the plasma chamber. After the pressure became stable at 1 Torr, the power supply was switched on for 10 minutes. This experiment was carried out with a wide range of plasma power $(50,100,150,200$ and $250 \mathrm{~W})$.

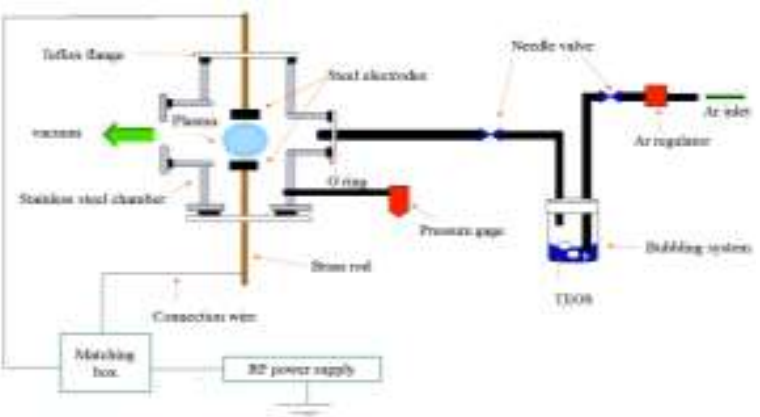

Figure 1. The schematic diagram of the plasma deposition cell.

\subsection{Characterization methods}

2.4.1. Scanning electron microscopy (SEM) and energy-dispersive $X$-ray spectroscopy (EDX)

The surface morphology of samples was examined using SEM (FEI-inspect -S50, 
Denmark) with magnification rang to 100,000 x. SEM is attached with an EDX unit with acceleration voltage $30 \mathrm{KV}$ and used for elemental analysis of the treated sample compared to the untreated ones.

\subsubsection{Electrochemical measurements}

Electrochemical investigations were carried out using a Potentiostat / Galvanostat / FRA analyzer (Auto lap PGSTAT 30, Netherlands), in the classical three-electrode cell containing saturated calomel reference electrode (SCE) and a platinum grid as a counter electrode. Moreover, the surface area of the working electrode was $1 \mathrm{~cm}^{2}$.

Two electrochemical techniques were used for the evaluation of corrosion protection efficiency of treated samples, one of them is electrochemical impedance spectroscopy (EIS). The impedance measurements were carried out by applying an AC excitation of $10 \mathrm{mV}$ amplitude (peak-to-zero) of sinusoidal voltage in the frequency range from $100 \mathrm{kHz}$ to $10 \mathrm{~m}$ Hz. The samples were immersed in a3.5\% $\mathrm{NaCl}$ aqueous solution for 30 minutes to acquire a steady state before measurements. All measurements were completed at room temperature $\left(30^{\circ} \mathrm{C}\right)$.

The obtained impedance data were analyzed using $\mathrm{Z}$ view 2 software to achieve the best fitting and calculate EIS associated parameters. The inhibition efficiency ( $\eta$ EIS) was calculated using Eq. (1).

$$
(\eta \text { EIS })=\left[1-\left(R_{c t}^{\circ} / R_{c t}\right)\right] \times 100
$$

Where $\mathrm{R}_{\text {ct }}^{\circ}$ and $\mathrm{R}_{\mathrm{ct}}$ are the charge transfer resistance of untreated and treated steel samples, respectively.

Potentiodynamic polarization is also used to evaluate corrosion performance and was performed by scanning applied potential from 0.3 to $1 \mathrm{mV}$ at a scan rate $2 \mathrm{mV} \mathrm{s}^{-1}$. The inhibition efficiency $\left(\eta_{\mathrm{pol}}\right)$ was calculated from Eq. (2).

$\left(\eta_{\text {pol }}\right)=\left[1-\left(I_{\text {corr }} / \mathrm{i}^{\circ}\right.\right.$ corr $\left.) \times 100\right]$

Where $i^{\circ}$ corr and $i_{\text {corr }}$ are the corrosion current densities of untreated and treated samples, respectively.

\section{RESULTS AND DISCUSSION}

\subsection{Surface morphology}

Surface topography was investigated using SEM. Fig. 2 exhibits the morphological characteristics of treated and untreated steel samples before and after immersion in 3.5\% $\mathrm{NaCl}$ solutions for $24 \mathrm{~h}$ with power inlet 100 and $250 \mathrm{~W}$. It is seen that the untreated steel sample before immersion was smooth and pits free (Fig.2a). The treated sample at $100 \mathrm{~W}$ exhibit that the steel surface is covered with a smooth, dense, and homogeneous film, as seen in Fig 2b. Conversely, the film obtained with $250 \mathrm{~W}$ was non-uniform. It contains some cracks and gaps as shown in Fig.2c. This observation indicates the film morphology strongly depends on the plasma power. Indeed, the raising of power creates high energized ions that allow to sustains reactions in the gas phase and little bet of materials were deposited at the film [19]. Also, the energized ions may collide with the film which previously deposited causing ruptures and cracks upon it [20].

Fig. $2 \mathrm{~d}$ reveals the surface morphology of the untreated sample (blank) after dipped in the corrosive solution. The untreated surface appears damaged and pitted, because of chloride ions attack on the steel surface. The plasma-treated sample at $100 \mathrm{~W}$ seen be protected and little affected by the corrosion medium as presented in Fig. 2e. While a large damage area of the film was obtained with 250 $\mathrm{W}$ (Fig. 2f), that might be related to the fragmentation of the monomer followed by poly-recombination due to the high energy of plasma leading to a poor quality deposited film (irregular structure) [21, 22]

\subsection{Elemental analysis using energy dispersive analysis of X-ray (EDX)}

EDX spectrum analysis provides a clear understanding of the elemental composition of the steel surface. The obtained results were revealed in Table 1. Silicon, oxygen and carbon were detected in all treated samples. Moreover, the atomic percentages (At \%) of previous elements follow a regular trend based on plasma power.

The highest $\mathrm{Si}, \mathrm{O}$, and $\mathrm{C}$; and lowest $\mathrm{Fe}$ contents were observed in the treated sample 

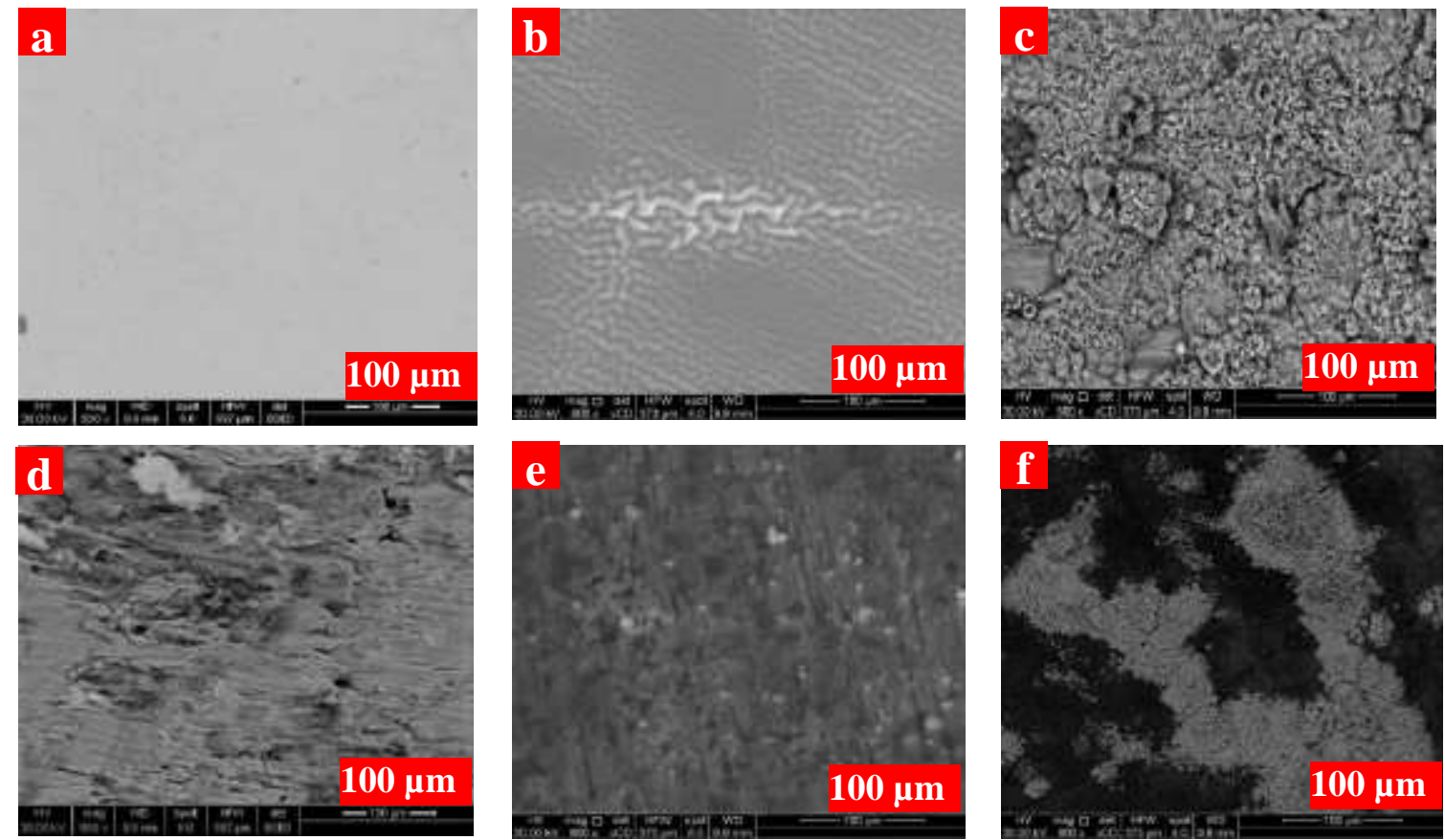

Figure 2. SEM image of carbon steel sample as: blank (untreated) (a), treated sample with $100 \mathrm{~W}$ (b), 250 W (c); where these samples after 24-hour immersion in 3.5\% NaCl solution: blank (d), $100 \mathrm{~W}$ (e), $250 \mathrm{~W}$ (f).

with power $100 \mathrm{~W}$. On the other hand, the prepared sample with $250 \mathrm{~W}$, the atomic percentage of $\mathrm{Si}$ and $\mathrm{O}$ are low while the carbon content is undetectable compared to that sample which made with $100 \mathrm{~W}$.

Theoretically, the atomic percent should be in the TEOS as: $07.7 \mathrm{Si}, 30.8 \mathrm{O}$ and $61.5 \mathrm{C}$.

The data obtained confirm that an irregular film was obtained with high power inlet than $100 \mathrm{~W}$.

From this data, it might be proposed that the composition of the deposited layer is silicon oxy carbide like matrix.

Table 1. Elements composition (atomic \%) of deposited films with different power compared to the blank sample obtained by EDX analysis.

\begin{tabular}{c|c|c|c|c}
\hline \multirow{2}{*}{$\begin{array}{c}\text { Plasma } \\
\text { power } \\
(\boldsymbol{W})\end{array}$} & \multicolumn{4}{|c}{ Element (At\%) } \\
\cline { 2 - 5 } & Fe & Si & O & C \\
\hline blank & 99.36 & - & - & 00.64 \\
\hline 50 & 76.46 & 2.75 & 4.63 & 16.16 \\
\hline 100 & 76.80 & 6.73 & 5.67 & 10.80 \\
\hline 150 & 90.33 & 2.54 & 2.35 & 04.78 \\
\hline 200 & 93.62 & 1.49 & 2.13 & 02.76 \\
\hline 250 & 98.02 & 0.84 & 1.14 & - \\
\hline
\end{tabular}

\subsection{Electrochemical investigations}

\subsubsection{Potentiodynamic polarization measurements}

The potentiodynamic polarization curves for carbon steel with and without the plasma treatment in $3.5 \% \mathrm{NaCl}$ at $30 \circ \mathrm{C}$ are presented in Figure 3. The electrochemical parameters extracted from this figure such as corrosion potential $\left(\mathrm{E}_{\text {corr }}\right)$, corrosion current density $\left(\mathrm{I}_{\text {corr }}\right)$, corrosion rate $\left(\mathrm{K}_{\text {corr }}\right)$, corrosion inhibition efficiency $(\eta$ pol $\%)$, anodic and cathodic Tafel slope (Ba, Bc), are given in Table 2. It was noted that all polarization curves shift to lower current densities by plasma treatment. However, the depletion in current density is directly proportional to the power of plasma and reaching a minimum at $100 \mathrm{~W}$ of power. The reduction of $I_{\text {corr }}$ indicates that the deposited thin film of plasma TEOS has an ability to protect the carbon steel in the corrosive solution with protective efficiency 97.29 and $90.58 \%$ for 100 and $50 \mathrm{~W}$, respectively. However, when the power was reduced to $50 \mathrm{~W}$ the energy of ions in the plasma sheath is not satisfactory enough to decompose TEOS in the gas phase which minimizes the deposition rate of film. 


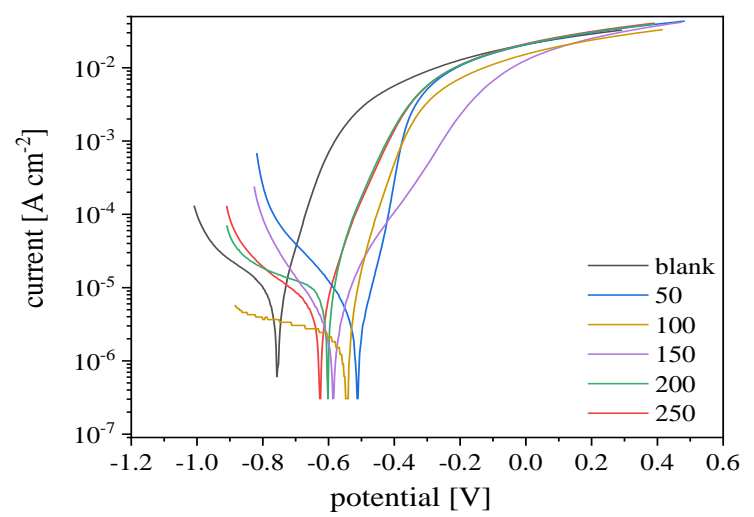

Figure 3. Potentiodynamic polarization curves of untreated and plasma-treated steel with different plasma power in $3.5 \% \mathrm{NaCl}$ at room temperature $\left(30^{\circ}\right)$.

The values of $E_{\text {corr }}$ for the treated steel is higher than that obtained for blank. The corrosion potentials $\left(\mathrm{E}_{\mathrm{corr}}\right)$ values for the treated samples in a $3.5 \% \mathrm{NaCl}$ solution are increased with increasing the plasma power as shown in Table 2. The increase in $E_{\text {corr }}$ and decrease in $\mathrm{I}_{\text {corr }}$ under plasma treatment and reach to the optimum at plasma power (100W) which proved to be effective in protecting the substrate from the corrosive medium.

\subsubsection{Electrochemical impedance spectroscopy (EIS)}

The effect of plasma on the corrosion behavior of mild steel in $3.5 \% \mathrm{NaCl}$ was also investigated by electrochemical impedance spectroscopy. The EIS data are given as Nyquist and Bode-phase angle plots (Figs.4 and $5)$, respectively, in $3.5 \% \mathrm{NaCl}$ at $30{ }^{\circ} \mathrm{C}$. The Nyquist plot shows semicircular hoop over the entire frequency range which may be attributed to the occurrence of the charge transfer process in the solution which controls the corrosion mechanism of steel [13].

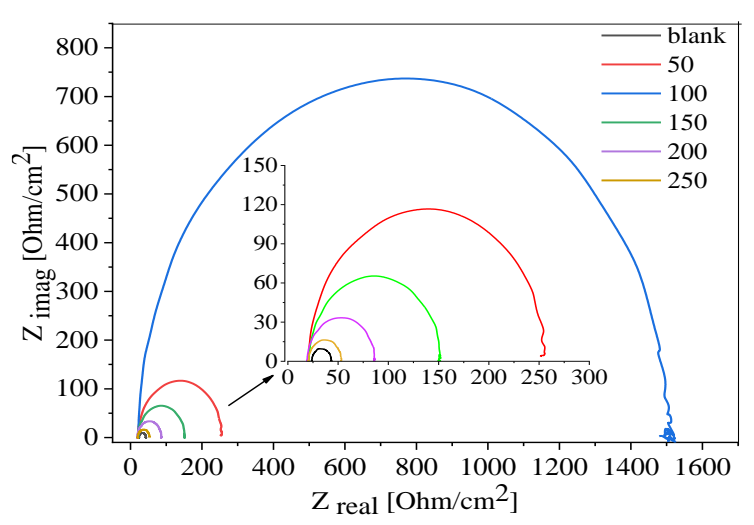

Figure 4. Nyquist plot of base material and plasmatreated samples in $3.5 \% \mathrm{NaCl}$ at room temperature $\left(30^{\circ}\right)$.

Moreover, the EIS parameters such as double-layer capacitance $\left(\mathrm{C}_{\mathrm{dl}}\right)$, charge transfer resistance $\left(\mathrm{R}_{\mathrm{ct}}\right)$, and efficiency of inhibition

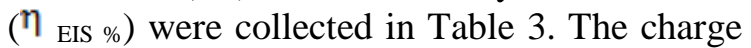
transfer resistance of carbon steel was increased significantly by plasma treatments, and the enhancement degree was increased to maximum as the power of plasma reached to (100W). Indeed, as mentioned before, the increase of plasma power creates highly energetic ions in the gas phase which prevents the deposition of a uniform protective film over the steel surface [23]. Moreover, this hypothesis is good agreement with data obtained by SEM that mentioned before. The double-layer capacitance $\left(\mathrm{C}_{\mathrm{dl}}\right)$ is used to display the capacitance of a double layer formed at the interface between the steel surface and the electrolyte [24]. Therefore, that decreased after plasma deposition indicating to hydrophobic nature of the deposited layer that's slowing down the interaction between the electrolyte and coated steel providing good protection against corrosion.

Table 2. Potentiodynamic polarization associated parameters of low carbon steel coated by plasma deposited thin films at various plasma power in an aqueous solution of $3.5 \% \mathrm{NaCl}$ at room temperature.

\begin{tabular}{|c|c|c|c|c|c|c|}
\hline $\begin{array}{c}\text { Plasma power } \\
\text { (W) }\end{array}$ & $\begin{array}{c}i_{\text {corr }} \\
\left(\mu A / \mathrm{cm}^{2}\right)\end{array}$ & $\begin{array}{c}E_{\text {corr } V S .} \\
S C E(m V)\end{array}$ & $\begin{array}{c}B_{a} \\
\left(m V \cdot \text { dec }^{-1}\right)\end{array}$ & $\begin{array}{c}B_{c} \\
\left(m V \cdot \text { dec }^{-1}\right)\end{array}$ & $\begin{array}{c}K \\
\text { (mm/year) }\end{array}$ & $\begin{array}{l}\eta_{p o l} \\
(\%)\end{array}$ \\
\hline blank & 12.001 & -0.8093 & 115 & -203 & 0.08981 & 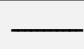 \\
\hline 050 & 01.130 & -0.5144 & 171 & -134 & 0.00845 & 90.58 \\
\hline 100 & 00.325 & -0.5410 & 025 & -222 & 0.00243 & 97.29 \\
\hline 150 & 01.900 & -0.5872 & 072 & -081 & 0.01422 & 84.16 \\
\hline 200 & 03.552 & -0.6052 & 173 & -066 & 0.02658 & 70.40 \\
\hline 250 & 06.932 & -0.6540 & 056 & -063 & 0.05188 & 42.23 \\
\hline
\end{tabular}




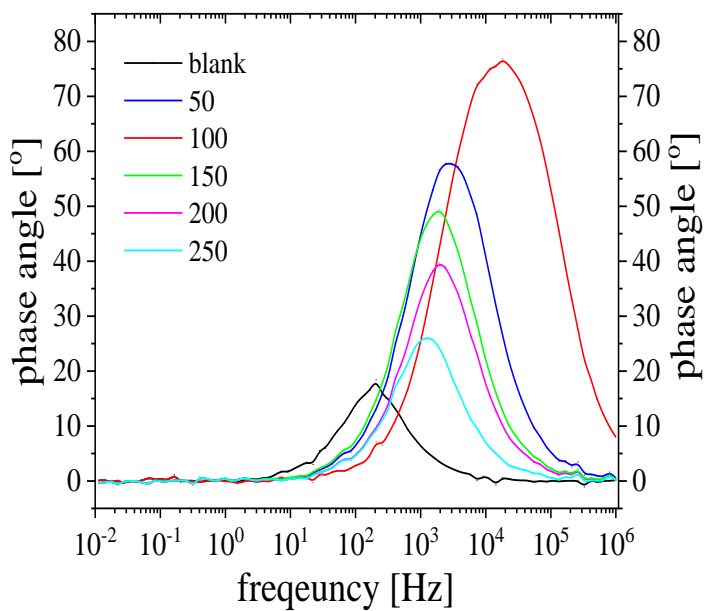

Figure 5. Bode plot of untreated and plasmatreated samples in $3.5 \% \mathrm{NaCl}$ at room temperature $\left(30^{\circ}\right)$.

Simultaneously, in the Bode-phase diagram the carbon steel in corrosive solution exhibit one peak at the middle frequency range, which refers to the changes in the phase angle caused by substrate-electrolyte interactions (Figure 5). This peak is still detected after plasma deposition but shifted to high frequency region and gets more intense in all treated samples. The simultaneous shift of the phase angle to high frequency region is because of coating/electrolyte interface. Also, this shift was reaching the maximum in the deposited sample with $100 \mathrm{~W}$. This behavior might be related to the better adhesion of the coating and reveal a better performance of the sample in the corrosive medium.

The obtained EIS data were analyzed using an electrical equivalent circuit to achieve the best fitting of these data. The Randle circuit (Fig. 6) consists of two resistances and capacitance. Rs is the solution resistance between the reference and the working electrodes, $R_{c t}$ represents the charge-transfer resistance at the metal/electrolyte interface. The capacitance $\mathrm{C}_{\mathrm{dl}}$ signifies the interface between the working electrode and the corrosive electrolyte.

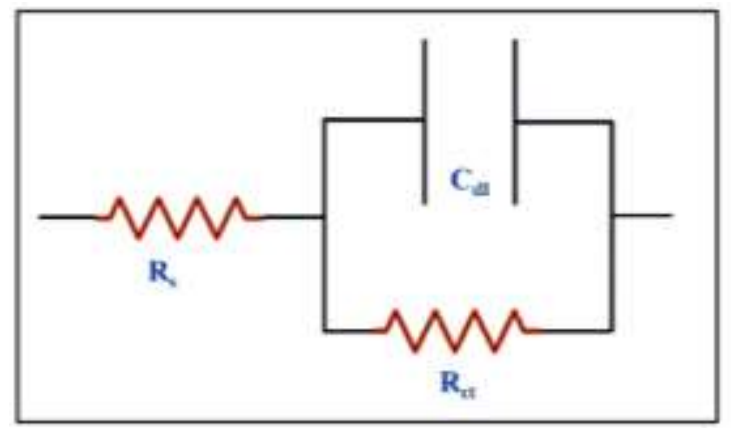

Figure 6. The electrical equivalent circuit (Randal equivalent circuit model) used to fit EIS data.

Table 3. EIS parameters of low carbon steel coated by plasma deposited thin $\mathrm{SiO}_{x} \mathrm{C}_{y}$ films with different power in the aqueous solution of $3.5 \% \mathrm{NaCl}$ at room temperature.

\begin{tabular}{c|cccc}
\hline $\begin{array}{c}\text { Plasmapower } \\
(\boldsymbol{W})\end{array}$ & $\begin{array}{c}\boldsymbol{R}_{\boldsymbol{s}} \\
(\boldsymbol{\Omega} \\
\left.\boldsymbol{c m}^{\mathbf{2}}\right)\end{array}$ & $\begin{array}{c}\boldsymbol{R}_{\boldsymbol{c t}} \\
\left(\mathbf{\Omega} \boldsymbol{c m}^{2}\right)\end{array}$ & $\begin{array}{c}\boldsymbol{C}_{\text {dl }} \\
\left(\boldsymbol{\mu} \boldsymbol{c m} \boldsymbol{c m}^{-}\right.\end{array}$ & $\begin{array}{c}\eta_{\text {EIS }} \\
\boldsymbol{\%}\end{array}$ \\
\hline blank & 23.80 & 0019.37 & 56.924 & - \\
$\mathbf{5 0}$ & 20.79 & 0235.20 & 00.819 & 91.76 \\
$\mathbf{1 0 0}$ & 22.46 & 1485.00 & 00.0517 & 98.69 \\
$\mathbf{1 5 0}$ & 21.20 & 0130.50 & 01.800 & 85.15 \\
$\mathbf{2 0 0}$ & 19.34 & 0066.98 & 02.500 & 71.08 \\
$\mathbf{2 5 0}$ & 20.60 & 0032.80 & 06.280 & 40.94 \\
\hline
\end{tabular}

\section{CONCLUSIONS}

Silicon oxy carbide thin films were deposited successfully on the steel substrate by RF/TEOS plasma at room temperature. The structure/property relationships of treated samples were studied in dependence on the plasma power. The deposited films exhibit a uniform surface without apparent pinholes. Polarization and electrochemical impedance spectroscopy analysis indicates that thin TEOS films act as a barrier layer between metal/solution interfaces that enhances the corrosion resistance of carbon steel. The deposited film which prepared with $100 \mathrm{~W}$ is the best condition with protective efficiency more than $98 \%$ at room temperature. Moreover, these films can provide good anticorrosion property with a cost-effective approach. 


\section{REFERENCES}

[1] R. C. C. Rangel, N. C. Cruz, A. Milella, F. Fracassi, and E. C. Rangel, "Barrier and mechanical properties of carbon steel coated with $\mathrm{SiOx} / \mathrm{SiOxCyHz}$ gradual films prepared by PECVD," Surface and Coatings Technology, vol. 378, p. 124996, (2019).

[2] E. Shekari, F. Khan, and S. Ahmed, "Economic risk analysis of pitting corrosion in process facilities," International Journal of Pressure Vessels and Piping, vol. 157, pp. 51-62, (2017).

[3] S. Shi, Y. Zhao, Z. Zhang, and L. Yu, "Corrosion protection of a novel $\mathrm{SiO} 2$ @.PANI coating for Q235 carbon steel," Progress in Organic Coatings, vol. 132, no. February 2018, pp. 227-234, (2019).

[4] F. Wang, F. Zhang, L. Zheng, and H. Zhang, "Structure and corrosion properties of $\mathrm{Cr}$ coating deposited on aerospace bearing steel," Applied Surface Science, vol. 423, pp. 695-703, ( 2017).

[5] G. Huang et al., "Corrosion resistance improvement of 45 steel by Fe-based amorphous coating," Vacuum, vol. 153, pp. 39-42, (2018).

[6] Y. Xu, M. Li, and M. Liu, "Corrosion and fouling behaviors of phosphatized Q235 carbon steel coated with fluorinated polysiloxane coating," Progress in Organic Coatings, vol. 134, no. May, pp. 177-188, (2019).

[7] S. R. Nayak and K. N. S. Mohana, "Corrosion protection performance of functionalized graphene oxide nanocomposite coating on mild steel," Surfaces and Interfaces, vol. 11, pp. 63-73, (2018).

[8] R. Babaei-Sati, J. Basiri Parsa, and M. VakiliAzghandi, "Electrodeposition of polypyrrole/ metal oxide nanocomposites for corrosion protection of mild steel-A comparative study," Synthetic Metals, vol. 247, no. August 2018, pp. 183-190, (2019).

[9] W. Wang, D. Wang, and F. Han, "Improvement of corrosion resistance of twinning-induced plasticity steel by hotdipping aluminum with subsequent thermal diffusion treatment," Materials Letters, vol. 248, pp. 60-64, (2019).

[10] M. Abuín, A. Serrano, J. Llopis, M. A. García, and N. Carmona, "Silica doped with lanthanum sol-gel thin films for corrosion protection," Thin Solid Films, vol. 520, no. 16, pp. 5267-5271, (2012).

[11] H. Cheraghi, M. Shahmiri, and Z. Sadeghian, "Corrosion behavior of $\mathrm{TiO} 2-\mathrm{NiO}$ nanocomposite thin films on AISI $316 \mathrm{~L}$ stainless steel prepared by sol-gel method," Thin Solid Films, vol. 522, pp. 289-296, (2012).

[12] Q. P. Wei, Z. M. Yu, M. N. R. Ashfold, L. $\mathrm{Ma}$, and $\mathrm{Z}$. Chen, "Fretting wear and electrochemical corrosion of well-adhered CVD diamond films deposited on steel substrates with a WC-Co interlayer," Diamond and Related Materials, vol. 19, no. 10, pp. 1144-1152, (2010).

[13] H. Ghorbani, A. Abdollah-zadeh, F. Bagheri, and A. Poladi, "Improving the bio-corrosion behavior of AISI316L stainless steel through deposition of Ta-based thin films using PACVD," Applied Surface Science, vol. 456, no. June, pp. 398-402, (2018).

[14] A. Delimi, Y. Coffinier, B. Talhi, R. Boukherroub, and S. Szunerits, "Investigation of the corrosion protection of SiOx-like oxide films deposited by plasma-enhanced chemical vapor deposition onto carbon steel," Electrochimica Acta, vol. 55, no. 28, pp. 8921-8927, (2010).

[15] M. Abu-Saied, A. Fahmy, N. Morgan, W. Qutop, H. Abdelbary, and J. F. Friedrich, "Enhancement of Poly(vinyl chloride) Electrolyte Membrane by Its Exposure to an Atmospheric Dielectric Barrier Discharge Followed by Grafting with Polyacrylic Acid," Plasma Chemistry and Plasma Processing, vol. 39, no. 6, pp. 1499-1517, (2019).

[16] Y. Sen Lin, C. H. Chang, and T. J. Huang, "Enhanced corrosion protection of cold rolled steel by low-temperature plasma cleaning and plasma polymerization," Surface and Coatings Technology, vol. 200, no. 16-17, pp. 4929-4938, (2006).

[17] S. Saloum, B. Alkhaled, W. Alsadat, M. Kakhia, and S. A. Shaker, "Plasma polymerized hexamethyldisiloxane thin films for corrosion protection," Modern Physics Letters B, vol. 32, no. 3, pp. 1-9, (2018).

[18] S. Ponton et al., "Investigation of the densification mechanisms and corrosion resistance of amorphous silica films," Journal of Non-Crystalline Solids, vol. 515, no. February, pp. 34-41, (2019). 
[19] J. Zhang, Q. Chen, Y. Zhang, F. Liu, and Z. Liu, "The power source effect on SiOx coating deposition by plasma enhanced chemical vapor deposition," Thin Solid Films, vol. 517, no. 14, pp. 3850-3853, (2009).

[20] M. Abbasi-Firouzjah, S. I. Hosseini, M. Shariat, and B. Shokri, "The effect of TEOS plasma parameters on the silicon dioxide deposition mechanisms," Journal of NonCrystalline Solids, vol. 368, no. 1, pp. 86-92, (2013).

[21] A. Fahmy, M. Abu - Saied, N. Morgan, W. Qutop, and H. Abdelbary, "Polyvinyl Chloride Membranes Grafting With Polyacrylic Acid Via Ar-Plasma Treatment," Al-Azhar Bulletin of Science, vol. 30, no. 1, pp. 81-89, (2019).

[22] A. Fahmy, K. S. El-Nasser, I. O. Ali, T. M. Salama, K. Altmann, and J. Friedrich, "Tuned interactions of silver nanoparticles with ZSM-5 zeolite by adhesion-promoting poly(acrylic acid) deposited by electrospray ionization (ESI)," Journal of Adhesion Science and Technology, vol. 31, no. 24, pp. 2641-2656, (2017).

[23] A. Fahmy, T. A. Mohamed, and J. F. Friedrich, "XPS and IR studies of plasma polymers layer deposited from allylamine with addition of ammonia," Applied Surface Science, (2018).

[24] T. Rabizadeh and S. K. Asl, "Casein as a natural protein to inhibit the corrosion of mild steel in $\mathrm{HCl}$ solution," Journal of Molecular Liquids, vol. 276, pp. 694-704, (2019).
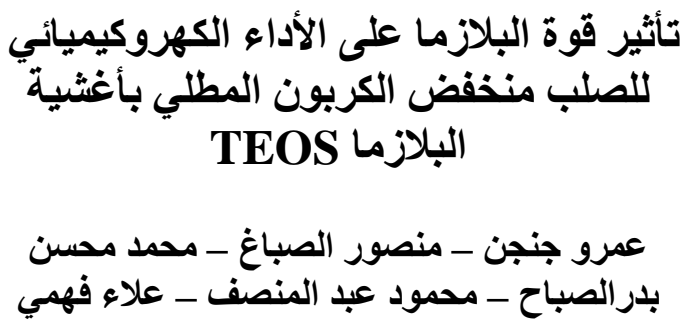

قسم الكيمياء ـ كلية العلوم - جامعة الازهر بالقاهرة

الملخص العربي

تم در اسة الخصائص الكهروكيميائية لعينات الصلب الكربوني المطلية بأغشية أوكسي كربيدالسيليكون وذللك من أجل تقيميها كطلائات مضادة للتآكل. تم ترسيب هذبي التهبه الأغشية على عينات الصلب منخفض الكربون بواسطة

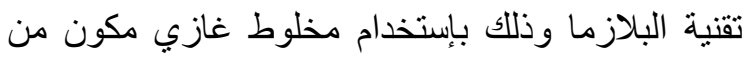

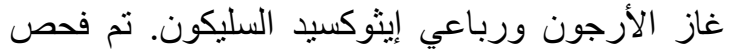
التركيب الكيميائي للأغثية المُرسبة بورينية اسطة التحليل الطيفي للأشعة السينية (EDX) إلى جانب الفحص باستخدام المجهر الإلكثروني (SEM) . وتشير نتائج المجهر الإلكتروني إلي تكون طبقة متجانسة وخالية من الثقوب من أوكسي كربيد السيليكون على سطح الصلب بعد معالجتة بالبلاز ما. أيضـا تم إختبارمقاومة التآكل لهذة الطلاءعات بواسطة تقنيتي التحليل الطيفي الكهروكيميائي وإستقطاب الجهد الديناميكي في محلول كلوريد الصوديوم بتركيز 3.5٪

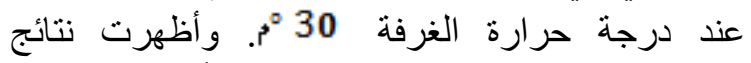

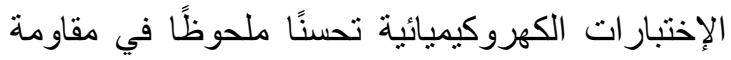

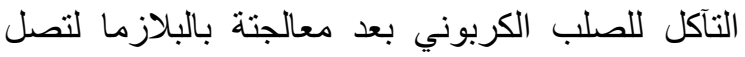

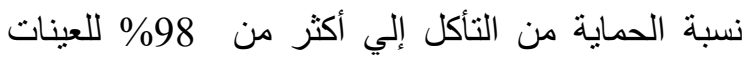

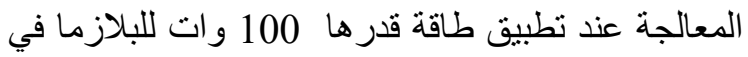
درجة حرارة الغرفة. 